\title{
The Ethics of Argument: Plato's Gorgias and the Modern Lawyer
}

\author{
James Boyd White $\dagger$
}

Plato's Gorgias" is about the "ethics" of argument in a literal sense of that term (which in Greek means both "habit" and "character") for the main issue to which it returns again and again is the kind of character a person defines for himself and offers to others-the kind of life and community he makes-when he chooses to think and talk in one way rather than in another. This is Plato's concern from the very beginning when Socrates gives Chaerephon the seemingly innocuous, but in fact deeply threaten-

$\dagger$ Professor in the Law School, the College, and the Committee on the Ancient Mediterranean World, The University of Chicago. The translations are my responsibility, but I wish to thank Stanley Szuba for his helpful assistance with them, and to thank him, Robert Kaster, James Redfield, Donald Regan, Ernest Wolf, and the members of the Seminar for Contemporary Social and Political Theory at The University of Chicago for helpful comments on earlier drafts.

This paper is a version of a chapter in my forthcoming book, When Words Lose Their Meaning: Constitutions and Reconstitutions of Language, Character, and Community (to be published in 1983 by The University of Chicago Press).

1 The Gorgias is one of Plato's early dialogues, written probably in the 380's (B.C.). The standard Greek text is Plato, Gorgias (E. Dodds ed. 1959). In addition, Plato, GorGIAS (T. Irwin trans. 1979), provides a recent English translation with careful analysis of particular passages.

Gorgias of Leontini was born in Sicily early in the fifth century B.C. and lived to be over one hundred years old. He came to Athens for the first time in 427 B.C., making a great impression with his oratory. He was a contemporary of Protagoras, the sophist about whom Plato wrote a dialogue of that name, and is sometimes said to have been a sophist, too. But Gorgias' interest was less in the sophistic devices of reasoning by which the weaker case could be made to appear the stronger than in the emotional power of rhythmic and musical speech. For our purposes it is best to take both Gorgias himself and the "rhetoric" of which he was the master as they are defined for us by the present text, rather than engaging in an independent historical inquiry about them. Of Callicles and Polus almost nothing is known beyond what Plato tells us here, except that Polus became a teacher of rhetoric. See Puato, Gorgias 6-15 (E. Dodds 1959); see also 3 W. Guthrie, A History of Greek Philosophy 262-74 (1962). On Gorgias himself, see G. Kennedy, The Art of Persuasion in Greece 6168 (1963).

The dramatic date of the dialogue is impossible to determine, since evidence within it supports dates ranging from 429 to 405 B.C. See Plato, Gorgias 17-19 (E. Dodds ed. 1959).

On the nature of dialectic, see R. Robinson, Plato's Earlier Dialectic (1953); H. Sinaiko, Love, Knowledge, and Discourse in Plato (1965).

Citations to the Gorgias will be made in the text by parenthetical references to the uniform Stephanus page numbers and letters. 
ing, direction to ask Gorgias "who he is," (447c) and it runs through to Socrates' defense of his own way of life, despite its terrible costs, at the end. (521a-27e)

In the Gorgias Plato focuses upon two contrasting ways of speaking, of being, and of establishing community with others, both of which can be described as forms of argument: "rhetoric," which he attacks, and "dialectic," which he defends and intends to exemplify. Of rhetoric there are three representatives: Gorgias, the Sicilian visitor to Athens and one of the first teachers of rhetoric; Polus (which means the "colt"), his brash young student; and Callicles, a mature practitioner of the rhetorician's art. Opposed to them are two exemplars of dialectic: Socrates, in relation to these interlocutors; and Plato, in relation to the reader.

In what follows I shall analyze Plato's text and do my best to suggest a response to it. But I should say at the outset that for the modern lawyer and law teacher this is not merely an academic exercise, for we in fact are rhetoricians very much as Plato defines them. What is at stake for us in reading this dialogue is what it means to have devoted ourselves to the set of social and intellectual practices that define the profession of law. We have a special relation to this text, for we can in the full Platonic sense be refuted by it. In this crucial sense, the Gorgias is in my view the best and most powerful work I know on a subject usually talked about in other and very dreary terms, under the heading of "legal ethics."

\section{ThE Gorgias}

\section{A. The Form}

The Gorgias is a dialogue, not a treatise, and it is important to ask at the outset why Plato chooses to write this way, instead of simply telling us what he believes in some straightforward fashion. Is it his idea to make philosophy entertaining, to put a sugar coating on the dull pill of truth, or does this form have purposes of another sort? In particular, why do we have three interlocutors of such different capacity and character talking with Socrates on the same subject? This will mean that some arguments are brought up in different terms and contexts all over again and that some arguments raised early are later dropped and never answered. Indeed, the very topic of the dialogue seems never to stay fixed: now it is rhetoric, now pleasure, now what we mean by the shameful or the admirable, now whether it is important to be able to protect oneself against harm, and so on. Nor are the methods of argument all of a piece: sometimes Socrates engages in a logical refutation, 
sometimes he tells stories, sometimes he plays tricks, sometimes he makes speeches. What is worse, some of the arguments Socrates makes are plainly specious, and others one suspects to be so, though Plato never tells us which ones he regards as defective. Why does the Gorgias have this apparently unphilosophical form? What does Plato achieve by using it that he otherwise could not?

These questions obviously cannot be answered in a sentence or a paragraph, but instead should be taken as suggesting the sort of attention that the Gorgias will invite and reward. It may be helpful to suggest now, however, that the dialogue itself is meant to exemplify the kind of life Socrates calls "dialectic." The form of this text is not a primitive or bizarre method of setting forth a doctrine that Plato is too perverse or incompetent to say straight out; what it offers is an engagement in an activity, and this activity is its true subject. As we shall see, Socrates does occasionally say something to describe dialectic, but its clearest and truest definition is to be found not in what he says but in what he does.

I shall here be concerned with "rhetoric" and "dialectic" only as they are defined in this dialogue, not as they are treated by Plato or others elsewhere. ${ }^{2}$ It is worth observing, however, that certain aspects of the dialectical process exemplified in the Gorgias recur in Plato's other Socratic dialogues and are similar to Socrates' description of his way of life in the Apology. ${ }^{3}$ There we are told that Socrates would typically seek out a person who claimed to know how to do something-in the Gorgias, the teaching of rhetoric; elsewhere, generalship or mathematics or the teaching of virtue-and ask his interlocutor his central questions: who are you, what do you do, and what do you know? ${ }^{4}$ Since we all know how to do things that we cannot explain, about which we have never thought beyond saying "I am a banker" or "I am a surgeon," this line of questioning has the result of making conscious what before was not, the relation between self and culture. I am a football coach or a law professor, I say, but only then, when for Socrates that is not a sufficient answer, do I begin to realize that this identity is a cultural one, not necessary but chosen, and chosen by me without my wholly knowing or understanding it. In the ensuing conversation the interlocutor's account of himself and of his mo-

2 What Plato meant by "dialectic" changed substantially over his life. See, e.g., J. Raven, Plato's Thought in the Making (1965). My concern is only with the way it is defined in this dialogue.

- Plato, Apology (uniform Stephanus edition).

Id. at 21c-22e. 
tives is shown to make no sense even in its own terms; it is seen to be internally incoherent. The one who claims to know, knows nothing after all. This is the elenchus or refutation of which Socrates repeatedly speaks (458a), and it is the heart of dialectic. It results in a mortification or humiliation, and of a special kind, for one is mortified by the invocation not of new facts or ideas but of what one already knows or claims to know. One part of the self is appealed to against another part, and in the process a previously unrecognized self-contradiction is revealed.

The intellectual process by which this aspect of dialectic typically works is a movement from a point of disagreement between Socrates and his interlocutor to a more general proposition that both accept; this point of agreement is then shown, by reasoning sometimes sound, sometimes fallacious, to lead to conclusions opposite to those previously asserted by the interlocutor. In the process, the language of the interlocutor is remade, converted into what are called paradoxes, that is, previously impossible or unimaginable propositions that he must now accept or that he is at least incapable of rationally rejecting. The effect of this process is to disturb the relation between self and language, to break down the sense of natural connection and coherence between them. One comes suddenly to see both self and language as uncertain, as capable of being remade in relation to each other. The true aim of a dialogue that works this way, of the Gorgias among others, is nothing less than the shared reconstitution of self and language.

\section{B. The Language}

To understand the ways in which Socrates works on his language and on the speakers whose attitudes are to some extent formed by that language - and the ways in which Plato works on the reader and his language-it is essential to have some knowledge of the central terms of the Greek language and culture and how they are related to one another. The reader will find, indeed, that many of the questions raised in this text are, at least in the first instance, really questions about the proper use of particular Greek words. Such questions invite responses that are partly objective or empirical, reporting what Greek usage in fact is, and partly normative or persuasive, asserting how a word ought to be used. In either case there is a sense in which some of the questions presented here can be asked only in Greek and can be answered only in Greek. Not surprisingly, the common English equivalents for the key terms-e.g., "good," "shameful," or "noble"-are hopelessly inadequate as substitutes, in part because they are laden 
with moralistic overtones that are wholly inappropriate to the Greek context. What kind of person would ever say in English, for example, that he "pursues the good"? Yet in Greek that would be a commonplace, almost a tautology: one central meaning of "what is good" is "what one pursues or chooses," whether or not it is "morally good." An English translation of the Gorgias thus tends to have an unreal and goody-goody quality, which makes one wonder how the questions that it addresses could possibly interest a serious person. In Greek, by contrast, the argument is vital and threatening, gripping the mind through its very language. Indeed the reason why, in the dialogues, people turn away from Socrates, and why, in the world, he was killed, is not that what he says is too vapid but that it is too real and threatening.

All of this presents obvious difficulties for the English-speaking reader. These cannot be entirely eliminated, but I will try to reduce them by providing some lexicographical information at the start; thereafter certain Greek terms will be used along with, or instead of, English substitutes.

The most important Greek terms of value used in the Gorgias are agathon ("good") and its opposite kakon ("bad"), and kalon ("noble") and its opposite aischron ("shameful"). 5 These words are the most powerful terms of praise and blame in the Greek of the time, operating as terms of final conclusion in an argument: if it is kakon or aischron, no one could want it; if it is agathon or kalon, everyone will want it, for that is what the terms mean. Not surprisingly, then, they have a very wide range of use and association, not wholly reproducible in English even by lengthy disquisition, let alone by bland substitutions such as the traditional ones given above. And as one would expect of such terms, within their ranges of meaning there are deep conflicts and contradictions that reflect tensions basic to the culture as a whole. The Gorgias is in an important sense about these words and others related to them: about what they should be taken to mean, how they should be defined or redefined; about the ways in which the contradictions they entail might be resolved; and about the patterns of meaning in which they should be arranged. Its object is to construct a coherent lan-

s Kakos is the masculine nominative singular, and will be used in this text when a person is referred to; kakon is the neuter singular, and will be used when an object or quality is meant. Similar endings have similar significance for the other adjectives as well.

For a thorough study of the development of the key terms of value in ancient Greek, the reader is referred to A. AdkINs, MERIT and RESPonsibility (1960), to which I am largely indebted for the brief version given in the text. 
guage of value out of the naturally complex and inconsistent materials of its time and, in so doing, to define new possibilities for the life of the self and of the community.

A short account of the meaning of the central terms identified above might go this way. The word agathon ("good") has one very powerful strain of meaning that has nothing to do with what we would call morally "good"; it is closer to our ideas of "successful" or "first class" or "someone that counts" or "something that matters." As applied to a person the term originally denoted the member of an aristocratic warrior class, and it commended qualities regarded as essential virtues by that class: bravery, martial prowess, skill at counsel, and the like. In this pattern of associations, kalon commends the conduct or condition of one who is agathos. One who is outside that aristocratic class or deficient in its virtues is kakos, and his conduct or condition is aischron. Thus, victory in battle or in games is kalon, defeat aischron; the powerful, superior man is agathos, the weak, inferior man kakos. We do have English uses of "good" similar to this use of agathos, such as "good at," "good for," "a good tackle," "a good shot," and so on. When agathon is used in this sense to describe the object of striving it means what men strive for in fact, and kakon accordingly means "what no one would choose." (In this sense Socrates' often repeated statement that no man willingly chooses the bad (kakon) says nothing surprising but just what the term implies.) When it is applied to objects or practices, agathon in this usage can often be equated with "useful" or "advantageous"; when it is applied to men it means something like "successful." Similarly kakon should be rendered not as "morally bad," but as "worthless" or "no good" or "harmful." Kalon, which characterizes the conduct of the agathos man as viewed by others, implies (as its opposite aischron also does) a social world functioning as the source of approval or disapproval. "Noble" sounds empty to modern ears; perhaps "admirable" is the best we can do. Aischron is usually translated as "shameful," often a rather weak word in our world; "degrading" or "humiliating" may catch the sense of it better. It is important that when applied to external features, kalon means what we would call "beautiful," and aischron "ugly."

These uses are far from modern experience. A few Americans, if they had access to the terms, might, I suppose, regard themselves as agathos by birth and regard others as kakos; many more might consider themselves as agathos by wealth (especially if they themselves had earned their money) or by power. This use of the word would contain almost nothing of what we mean by "good- 
ness"; it would not matter if the money were earned in the candy business or the arms trade, or the power acquired legally or through a corrupt political machine. ${ }^{B}$ Agathos is a term of what we weakly call prestige.

There are in Greek other uses of the words agathon, kakon, kalon, and aischron that commend the presence or decry the absence of what we would be more inclined to call moral virtues: lawfulness, mercy, a sense of community and equality, and the like. These can for our purposes be summed up, as Plato and Socrates do, under the headings of justice and temperance. The tension between these two kinds of usage creates a problem deep in Greek language and culture, which it is a central purpose of the Gorgias to address and to elaborate.

\section{The Structure}

The dialogue, you will remember, goes in outline something like this. When asked "who he is," as defined by what he does in the world, Gorgias says that he is a rhetorician and a teacher of rhetoric. (449a) In response to a series of questions put by Socrates, he defines rhetoric as the art of persuading others, especially those with power in the state, primarily about questions of justice and injustice; rhetoric itself is thus an enormous power, which can be used for good or ill. (449d-54b) It works not by imparting knowledge about such things as justice and injustice, but by giving rise to the desired opinions about them. (454e-55a) When Socrates asks whether the individual who is to practice this art must himself nonetheless know about the just and the unjust, the humiliating (aischron) and the admirable (kalon), the advantageous and the good (agathon), and the worthless and the bad (kakon), about which he is to persuade others, Gorgias says that of course a rhetorician must know these things, and that if a student comes to him who does not know them, Gorgias will teach him. (459d-60a)

Notice that Socrates does not now pursue the line of questioning obviously left open by Gorgias' response: what is the nature of "justice," how is it known, and how is it taught? That is because this dialogue is not about the nature of justice-for that see the Republic-but is about a prior question, the proper standing of talk about justice in the first place. When Gorgias concedes the

- One who has in this sense "made it" would in Greek terms be agathos by virtue of his power (dynamis), acquired by his brains (he is phronimos) and guts (he is andreios). 
importance of the question he concedes Socrates' essential point.7

Young Polus, eager to tangle with Socrates, now breaks in and rejects the concession that Gorgias has just made. He says that Gorgias is simply ashamed (aischunomai) to admit the truth, which is that a rhetorician need have no special knowledge of justice, injustice, and the rest, in order to practice the art of persuading people about them. (460b-60c) Socrates welcomes his participation, so long as Polus agrees to engage in the process of refutation by question and answer and to refrain from making long speeches. He can question or answer, as he chooses. (461d-62b) Polus elects to do the questioning, but quickly reveals that he has no idea at all how to do it; he ends up simply asking Socrates what kind of art he thinks rhetoric is. (462b-62e) In response Socrates makes a brief speech in which he says that it is not an art at all, but merely a knack, which has as its object the production of pleasure-in fact it is merely a form of flattery $(463 a-63 c),{ }^{8}$ as cosmetics and cookery are. $^{9}$

Socrates is now asked an amusingly confused series of questions by Polus, at the heart of which is the assertion that it must be a great thing to be a rhetorician, for they have so much power in the city that they are practically dictators. $(466 b-66 c)$ Socrates responds by asserting a set of paradoxical propositions, which Polus at first denies, but then is forced to concede. The first of these

I In the text Socrates also makes a stronger (but perhaps fallacious) claim, that since the rhetorician must know "just things" he will be just himself. (460a-60c) It follows that there can therefore be no unjust use of rhetoric, and this proves that rhetoric is after all not a neutral force which can be used either for good or for ill, but a way of achieving justice.

This may seem an impossible line of argument in English, and perhaps in Greek. It is best taken as a restatement of the well-known Socratic position that knowledge is virtue: i.e., knowledge of justice necessarily makes one just. This will itself make sense only if it is recognized that the Greek word for knowledge incorporates what we would call "moral" or "emotional" as well as "cognitive" elements, and is much more intimately tied to the idea of practice than most uses of "know" are in English. See J. Gould, The Development of Plato's Ethics (1955); M. O'Brien, The Socratic Paradoxes and the Greek Mind (1967).

s Though the translation is traditional, "flattery" is in fact too weak a word to render the sense of the Greek word kolakeia: "fawning" or "bootlicking" comes closer.

- Socrates explains that there are four great arts for the care of the body and soul: gymnastics and medicine, which maintain and cure the body; legislation and justice, which do the same for the soul. Each art has as its object the welfare either of body or soul; each also has a false imitator, which aims not at what is good, but only at what is pleasant. These are cosmetics, cookery, sophistic, and rhetoric. They are all knacks, not arts, for they can give no rational account of themselves or of their objects, and do not deal with cause and effect. They are all flatteries, because they aim at pleasure without consideration of what is best, and "I call that shameful (aischron)." (464b-65e)

Notice that here and elsewhere Socrates talks about the soul-what we might call the self-in terms one would expect to be used of the city, and vice versa. He makes no explicit defense of this usage here. Its fullest development is in Plato, REPUBlic 543a-69c. 
is that the rhetorician and the dictator have the least power in the cities of which they seem to be master (466d-68e), "for they do virtually nothing that they want to do, but only whatever they think best." (466e) ${ }^{10}$ (That is, they can do whatever they wish but still be mistaken about whether it will advance what they really want.) In a similar fashion Polus is led to concede that it is worse (more kakon) to do injustice than to suffer it, and that although the unjust man cannot be happy, he will be less wretched if he is punished than if he is not. $(469 a-79 e)^{11}$ These statements are paradoxical because the words for "doing injustice" and "punishing" have a substantial element that means "injure," without regard to what we would call right and wrong. In the competitive sense of "agathon" it cannot possibly be "better" to suffer an injury-a diminution of autonomy and power-than to inflict one.

Socrates compels these concessions in his usual manner: first by eliciting acquiescence in certain propositions that the interlocutor cannot deny, and then by showing that they lead to conclusions very different from what he had imagined. In this conversation the key admission is that although it is in Polus's view worse (more kakon) to suffer injustice, it is more ugly and humiliating (more aischron) to do injustice. (474c) Socrates shows that this is not a possible set of positions, because what is more aischron must also

10 Socrates supports the distinction between "what one wants to do" and "whatever one thinks best" by distinguishing between an activity and its object. (466e-68e) People take medicine to get well, make a voyage to get wealthy, and so on. And when a person does something on account of something else, he wants not what he does, but what he does it for. Who would want to take medicine or cross the mountains in winter for themselves alone? In the world there are only good (agathon) (in the sense of "advantageous") things, bad (kakon) things, and neutral (metaxu) things. And when people do neutral (metaxu) things on account of the good (agathon) things it is the good (agathon) things that they really want. This is how it is possible for a dictator to do "whatever he thinks best" and at the same time "what he does not want," that is, by being wrong about what he really wants, namely, the good (agathon). He cannot have much power if he cannot do what he wants. (467c-68c)

11 With respect to the desirability of being punished, Socrates leads Polus to agree that if someone punishes another justly (dikaios kolazein), the other suffers what is just (dikaion), and what is just (dikaion) is also kalon (admirable, noble, beautiful) and what is kalon is agathon (good), i.e., either pleasant or useful. Since punishment is no pleasure it must be beneficial. And the benefit is enormous because it is a relief from the greatest of evils (kakon), a miserableness not merely of body or condition, but of the very self. (477a) All these things being true, to use rhetoric to avoid just punishment is pointless; if it has a proper use, it is only to bring just punishment upon oneself and to deflect it from one's enemies. (480c-80d)

There is of course a possibility not considered here: that rhetoric might be used to deflect unjust punishment from oneself and one's friends. It is characteristic of Polus that he misses the point; it is later raised by Callicles and addressed by Socrates. See infra pp. 859-60. 
be more kakon. (474c-75d)

At this point Callicles intervenes. He rejects this concession, saying that Polus, like Gorgias, is ashamed (aischunomai) to admit what he really thinks, which is that it is obviously better both to do wrong rather than suffer wrong and to avoid punishment rather than endure it. (482d-82e) The defect in Socrates' refutation, he says, is that it confuses the categories of nature and convention: it is by nature kakon to suffer injustice; only by convention is it aischron to inflict it. If one looks to nature rather than to convention it is both more kakon and more aischron to suffer than to do injustice. (483a) That is the position Polus was ashamed to admit. As Socrates earlier claimed that whatever is aischron is kakon, Callicles here reverses the equation: what is kakon is aischron. The conventions that establish the sense of aischron used by Socrates and accepted by Polus, says Callicles, are the work of weak people who seek to protect themselves from their natural masters. (483b83c) Being inferior, they are happy enough to settle for a general equality. But nature itself declares that it is just for the better (the -more agathos) to have more than the worse (the more kakos), for the more powerful to have more than the less powerful. (483d) This is natural as opposed to conventional justice. (484a-84c)

Callicles in this way rejects the very language of morality upon which Socrates' refutation depends. He seeks to avoid the traps and limits of the language of his culture by standing outside it, claiming the power to remake his language to coincide with reality as he sees it.

Callicles' substantive position is one of radical hedonism: according to what he calls natural justice and excellence, one who wants to live correctly should allow his desires to be as great as possible, satisfying them as they arise, without attempting to restrain them (kolazein), but rather serving them with all his manliness and intelligence. (491e-92a) Of course this is not possible for most people, so out of shame (aischune) for their own weakness, the majority blame such a man and treat lack of restraint or licentiousness (akolasia) as shameful and ugly and humiliating (aischron). It is because of their own lack of manliness that they praise temperance and justice. (492a-92b) In the natural scheme of things wantonness and licentiousness (akolasia) and liberty, if supported by force, are virtue and happiness. (492c)

When asked whether or not some pleasures are better than others-how high does the pleasure of scratching an itch rank with him, for example? (494c-94e)_Callicles at first persists in refusing to acknowledge distinctions among them, and asserts that the good 
and the pleasant are the same. (494c-95b) But he is then made to admit, among other things, that the coward feels as much pleasure at the retreat of the enemy as the brave man does, perhaps even more, and that the foolish man is as capable of pleasure as the intelligent man: will Callicles therefore call the pleasures of such people good (agathon)? (497e-98c) If all pleasures are equally good (agathon), he must do so. As a consequence, however, the man called kakos because of his cowardice or stupidity becomes as agathos as the agathos man, an absolutely impossible position for Callicles, for whom the agathos man is above all manly, brave, and successful. (499b) But to accept the alternative, and admit that some pleasures are better than others, would be to accede to a standard of judgment of exactly the sort he has been at such pains to deny. (499b-99c) This in turn opens up the question by what art that standard is to be discovered and defined, which returns us to the subject of rhetoric and dialectic. $(500 \mathrm{a}-00 \mathrm{~d})$ Callicles thus begins as one who boldly claims to remake his language to accord with moral reality as he sees it, but quickly finds that he cannot escape his commitment to its central terms after all. He retreats into a sullen pretense of acquiescence. (501c)

Now that Callicles will no longer engage in conversation with him (505c-05e), Socrates himself speaks at length in favor of orderliness within the self and in the world. The unrestrained (akolastos) man whom Callicles admires cannot be a friend to man or god, for he is incapable of community. (507a-08b) As for his own alleged incapacity to protect himself against having injustice done to him $(521 b-21 d)$, Socrates says that the art of not suffering wrong requires either that one become an absolute dictator or that one seek to ingratiate oneself in every way with those who do have power, praising and blaming the same things, and thereby becoming like them. (510a) If those who have power are unjust, to protect oneself against suffering injustice will require that one become unjust oneself, which, as we have already seen, is the most kakon and aischron of things. $(510 \mathrm{~b}-11 \mathrm{a})^{12}$ One cannot protect oneself against

13 Socrates demonstrates this by questioning Polus about the terms agathon (good: opposed to kakon) and kalon (admirable or noble or beautiful: opposed to aischron). What is kalon, he says and Polus agrees, is so by virtue either of some use to which it may be put, or some pleasure it yields, or both. The opposite of what is kalon is aischron, which must therefore be characterized by the opposite of use and pleasure, namely by evil (kakon) or by pain. Since it has been agreed that to do injustice is more aischron than suffering it, it must exceed in pain or in evil, or in both. It is not in fact greater in pain, but less, so it must be greater in evil, i.e., more kakon. "I spoke the truth, then, when I said that neither I nor you nor any other man whatever would choose rather to do than to suffer injustice; for it is more 
the one injury without suffering the other and greater injury.

The alternative to such ingratiation, which makes one like the object of one's flattery, is to have the aim not of pleasing the people but of making them as good as possible (most agathos). (513e) This, in fact, is the aim of Socrates, and of dialectic, which means that he is one of the few, if not the only one, who practices the true art of statesmanship. (521d-21e) This also means that, as the world is, Socrates could not put up much of a defense if someone were to use the law unjustly against him (521e-22c); but he does not think that this is humiliating or shameful (aischron), as it plainly would be if he were unable to protect himself against the far greater evil of saying or doing unjust things. (522d-22e) Socrates then tells a story of the afterlife, in which a person's soul is judged naked, just as it is, for what it is; he says that this is the real trial for which he wishes to prepare himself, not some proceeding brought against him by his enemies at Athens. (523a-26d) He concludes by saying this:

Among the many arguments we have made, while the rest were being refuted (elenchomai), this alone stood firm: that one should avoid doing injustice more than suffering it and that more than anything it should be a man's object to be, not to seem, good (agathos), in public and in private; and if one becomes bad (kakos) in some respect, one must be punished or corrected (kolazesthai); and that the second good (agathon) after being just is to become so, and to be corrected (kolazesthai) by paying the penalty; ${ }^{[13]}$ and that one should

\section{kakon." (475e)}

In my view this proof is, as it seems to be, only a logical or verbal trick. That what is aischron must be kakon is true (even for Socrates) only for some meanings of the word aischron, and such identity as exists rests upon more substantial considerations than are revealed here. On the role of false proofs in the dialectic, see infra notes 17-18 and accompanying text. On this section of the dialogue, compare Vlastos, Was Polus Refuted?, 88 Am. J. PhILOLOGY 454-60 (1967) with $4 \mathrm{~W}$. GuThRIE, supra note 1, at 311-12.

13 If this still seems to the reader an unimaginable position, let me suggest that the question be framed with respect not to yourself, but to your child: would you prefer that he have a crime committed against him or that he commit a crime? Both are forms of unhappiness, obviously, but the Socratic question assumes that and asks which is worse. And to think about punishment, one might place it in the context of the family: with what sort of love for a child would a parent never punish him? When Socrates speaks of punishment here, it is not just any infliction of pain that he means, but pain inflicted with the idea of correction. The practical difficulty of creating a system of socially imposed punishment rationally based on that principle does not affect his immediate point. (Similarly, here and in colloquy with Callicles he assumes that there could be a "just" rhetoric, though in fact his arguments seem to demonstrate that this cannot be.) On punishment, see Morris, A Paternalistic Theory of Punishment, 18 Purl. Q. 263-71 (1981). 
shun all flattery of oneself or others, of the few or the many; and that rhetoric should always be used towards the end of justice as should every other activity. (527b-27c)

This is the way in which we should live, and call upon others to live, "not that which you trust and call upon me to share; for it is worth nothing, Callicles." (527e)

\section{Dialectic}

Throughout the dialogue Socrates is at pains to define what he calls "dialectic" as a way of thinking and living, and to oppose it to rhetoric. For example, he says at the beginning that he does not want to hear an oratorical display by Gorgias, but instead wishes to engage in conversation with him. (447c) When Gorgias subsequently makes great claims for the power of rhetoric, Socrates rather gently says that he would like to take issue with what Gorgias has said, for it does not seem consistent, but also that he does not want to be offensive. He adds that he himself welcomes being refuted (elenchomai) when he says something untrue and welcomes refuting others when they fail to speak the truth; if Gorgias is of the same mind they can proceed, otherwise they should let the conversation drop. (457c-58b) Only when Gorgias agrees to these conditions does Socrates begin his questioning. (458b)

Dialectic thus proceeds by question and answer, we learn, and its object is something called "refutation" or "correction." We discover something more about it when Polus seeks to establish that a man can be both unjust and happy by citing the instance of Archelaus, the tyrant of Macedonia. (470d) Socrates first speaks to Polus not about the merits of his claim, but about the method by which Polus is proceeding, saying that this sort of argument may be persuasive rhetorically, because perhaps most people would agree with it, but that it is no demonstration whatever in dialectic, because he, Socrates, does not agree with it, and a dialectical refutation (elenchos) requires that one make the other agree with what one says. (471e-72c) What matters between us is not the other witnesses who can be brought forward to support your view or mine, but whether you can make me your witness, or I can make you mine. For dialectic to exert its full force upon the individual mind, complete frankness is essential; it requires a kind of shamelessness in saying what one really thinks. Thus Gorgias and Polus perhaps avoid the full force of Socrates' mind by agreeing with him too readily, and Socrates welcomes Callicles' bluntness of speech (487d), for his candor may make possible a real engagement of 
mind with mind.

The aim of dialectic is to expose contradictions in one's thought, which to Socrates are contradictions in one's very self. $\mathrm{He}$ tells Callicles, for example, that he either must refute (exelencho) the argument that doing injustice is the worst of evils

or, Callicles himself will not agree with you, Callicles, but you will be in discord all your life; and yet I at least think it better that my lyre be out of tune and discordant, or a chorus I might equip be disharmonious, or that most men might disagree with me and say the opposite of what I say, than that I-just one man-be discordant with myself and say opposite things within myself. (482b)

Still, as I suggested above, the most important definitions of dialectic are actually to be found not in such statements as these, but in the activities presented in the text, those activities by which Socrates engages the minds of his interlocutors, and Plato the mind of his reader. What can be said of these ${ }^{14}$ What is the life exemplified here and how does the peculiar form of the dialogue work to express it? What kind of attention does this text invite, and what kind of meaning does it yield?

\section{A. Mind and Language: Dialectical Culture}

We can start with the paragraph quoted at the close of the summary given above. ${ }^{15}$ Here we have a set of propositions, each of which has been repeated over and over during the course of the dialogue; upon them Socrates now says that he confidently rests, however erroneous his other statements may have been. (527b) This paragraph is thus explicitly offered as the central statement of the text as a whole. But the statement is a strange one because all of the propositions it collects, as their earlier reception in the dialogue has made plain, are what is called, in Greek as well as in English, "paradoxical," that is, preposterous, "out of place," what no one would ever say. How can it possibly be more agathon (advantageous) and kalon (befitting to the powerful) and less aischron (humiliating) and kakon (worthless) to suffer wrong than to inflict

14 It is a tendency of the dialogues to call whatever kind of bad reasoning is at issue "sophistic" or "eristic" and to label any good reasoning "dialectic." See R. RoBINSon, supra note 1, at 70. For our purposes it is the way dialectic is defined in the performance that matters. In any event, it would be inconsistent with the way dialectic is exemplified here to expect a systematic definition.

15 See supra pp. 860-61. 
it? It seems that the words cannot bear the meanings given them. If the rest of the dialogue did not exist and these statements stood alone, they would seem crazy or meaningless. They could certainly not be taken seriously, for they arrange the materials of the culture in ways that are, in the first instance at least, simply impossible.

But this very fact suggests a way of understanding the aim of the dialogue as a whole: it is to offer the reader a set of experiences that so change his sense of things, including his sense of his language and himself, that when at the end these statements occur together as a kind of summary of what has been said over and over in various ways in the rest of the dialogue, they no longer seem paradoxical, but natural and coherent and powerful and clear. In this rather literal sense it can be said that the object of the dialogue is the making of a new language.

But what kind of language is this and how is it put together? It is important to see that this is for the most part not an artificial or theoretical language, based upon stipulative definitions that are then combined into propositions connected by the laws of logic, but is instead what might be called a natural or poetic language, in which terms have overlapping and inconsistent meanings, internal complexities and lacunae. Accordingly, in establishing this language the dialogue proceeds not by logical progression from premise to conclusion but in an associative fashion, with many repetitions of question, idea, and term, often leaving a subject only to return to it later, perhaps in a surprising way. It is full of play and paradox, and has the structure less of formal argument (as we usually think of it) than of a poem or drama or musical composition. The recurrences of terms and statements are not really repetitions after all, for they acquire new meaning from what else is said, as a metaphor or image or melody may do: at the end they make sense in a new way.

This view of the dialogue helps explain how Socrates can speak in the closing paragraphs so dismissively of the other statements he has made, when he suggests that they can perhaps be refuted. $(527 \mathrm{~b})^{16}$ The reason is that the relationship between those statements and what he says now is not one of logical proof (if it were, the validity of his conclusions would depend absolutely upon the validity of the earlier statements) but is both looser and more complex than that. Some of the "proofs" Socrates offered in the conversation were plainly specious; ${ }^{17}$ others we suspected to be so;

16 See supra pp. 860-61.

37 See, for example, his "proof" to Polus that whatever is aischron must be kakon. 
and much was plainly motivated, in emphasis at least, by the nature of the social or dramatic moment. ${ }^{18}$ Here Socrates is saying that he knows all this, and that it does not matter. Not that we could not go back to those arguments and straighten them out, or at least arrive at a common view of them. But we cannot do everything at once, and the things he says now are those that matter most and that we know most clearly. Socrates here also tells us that he does not put the same weight on everything he says, as he would have to do if the form of the discourse were that of a mathematical or scientific proof; rather, he recognizes that we live in a world in which there are many things to say, of which some are jokes, some seem right but we are unsure, some seem dubious, and some are statements upon which one rests. It is the last that we are given in the final paragraph.

How is this language of paradox made? The most obvious method is overt definition of terms. Consider, for example, the definition of rhetoric that Socrates leads Gorgias to make at the very beginning. He starts with the question: with what is the art of rhetoric concerned? (449c-49d) With words (or speech)? But so in a way are many other arts; medicine, for example, uses words for diseases and for medicines. Might rhetoric be concerned with words abstracted from the material universe, with .words alone, so to speak? But so is arithmetic. Gorgias then says that what rhetoric offers is the power to persuade (peitho). (452e) But rhetoric is not the only art of persuasion, Socrates responds; in fact, every art that has a subject persuades with respect to that subject, as medicine does with respect to sickness and health. (453b) With respect to what subject does rhetoric persuade? Gorgias answers: with respect to what is just and unjust. (454b) And so on. This is a process of conceptual clarification that seems to be not threatening but helpful, a way of asking how we can accurately describe this part of our social and intellectual universe. The fact that the definitions are not stipulated, but cooperatively arrived at, means that it is not merely a clarification but an instruction in the processes of making things clear.

By contrast, in his definition of rhetoric as flattery ${ }^{19}$ Socrates is not drawing distinctions his interlocutors already make (perhaps without knowing it) so much as offering a new set of distinctions

(475a-75e)

18 See, for example, how gently Socrates lets Gorgias off the hook after refuting his arguments. (462e-62c)

10 See supra note 8 and accompanying text. 
for shared use, and doing so argumentatively, for he knows that the others will not see things in this way. Socrates similarly creates a new system of meaning when, in his engagement with Polus, he draws a distinction, not present in ordinary Greek, between doing "whatever one thinks best" and doing "what one wants." (467b)

The verbal "proofs" by which Socrates first establishes his paradoxes, that to do injustice is more kakon than to suffer it, and that to remain unpunished is more kakon for the wrongdoer than to be punished, ${ }^{20}$ are language-making of another kind: they overtly redefine the central value terms of the discourse, kakon and aischron, agathon and kalon. The same can be said of his proof to Callicles that the agathon and the pleasant must be different, which works by showing that pleasant coexists and coterminates with its opposite-as do the pleasure of drinking and the pain of thirst, for example-but the truly agathon does not. (495a-97d)

The effect of such proofs is peculiar. They produce acquiescence in the auditor, but of an unsatisfactory nature, for it arises not from conviction of the truth of what has been said, but from a sense that one cannot, at the moment anyhow, find an answer; not from belief, but from a sense of helplessness or defeat, as if at the hands of a mind more clever but not more sound. "I cannot answer but I still don't think it is right." The interlocutor is left wishing he could respond, knowing he cannot, and feeling frustrated and competitive. The effect of the "proof" is not to persuade, but to disorient him, to break down for the moment his sense of security and competence in the command of his language, to place him; as it were, nowhere, for he has nothing to say. All of this stimulates a need for a new sense of order and meaning. ${ }^{21}$

The reader on his part responds to these incompletely persuasive proofs in a similar way, to similar effect. He is frustrated both by the fact that neither Plato nor Socrates ever tells him which proofs are valid, and which are not, and by Socrates' dismissal of them all at the end, when he rests upon the central statements quoted above. ${ }^{22}$ This frustration has a purpose: it places responsibility for making sense of the arguments upon the reader, where it belongs. The unresolved question is left with him. And what does he do? He tries to test out the proofs, to decide which are falla-

20 See supra notes 11-12 and accompanying text.

21 For fuller statements of this process, see J. Gould, supra note 7; M. O'BrIEN, supra note 7; R. RoBinson, supra note 1; H. Sinalko, supra note 1 .

${ }^{22}$ See supra pp. 860-61. 
cious and which are valid. ${ }^{23}$ In doing this he is himself engaging in the activity of "refutation," which is a central part of the "dialectic" that it is the aim of the text to teach. Likewise, in his momentary identification with the confused and beaten interlocutor, the reader has experienced "being refuted," which is the other part of "dialectic." In such ways as this the text teaches its reader to think.

There is another movement in the dialogue, a refutation that operates not by redefining terms, but by returning to their accepted meanings. When Callicles is shown that his hedonism means that he must logically call the coward an agathos man, he recognizes that he, of all men, cannot do that, since his ethic is squarely based upon the traditional meaning of agathos, of which "brave" is a central component. (498a-98b) $\mathrm{He}$ who has so boldly claimed the power to remake his language, in competition with Socrates, is at the end unable to escape its central terms.

At times the language of Socrates is overtly poetic rather than logical, for example in the fable by which he seeks to show Callicles that the orderly (kosmios) are happier than the licentious (akolastos). Imagine two men, he says, each with a number of jars to be filled with milk, honey, wine, and the like. The jars of the one are sound and full, and he wants nothing; those of the other are leaky, and he must constantly struggle to keep them full. Does this image not portray the difference between the life of one who wants nothing and the life of one who is constantly scurrying after pleasures? (493d-94a) This fable is addressed not to the intellectual part of Callicles, but to the part of his mind that thinks and feels in images. It asks him to imagine, almost as if he were dreaming, what it would really be like to be a leaky jar, constantly running out and being refilled, and to be an owner, in frantic motion, constantly filling, or to be sound and full and at rest. As in a dream, the image of the self takes more than one form, here both jar and owner, and the story is about deep feelings of the self: anxiety and loss versus security and gain.

Or consider Socrates' discussion of Archelaus as an example of felicity (470d-72d): to ask a person to imagine himself as someone else, and to see how he would like it, is very different indeed from asking an abstract question. It invites a response of feeling and taste, as well as of intellect. Likewise, the imagined trial in the afterlife should be read not as a religious statement (especially not

${ }^{23}$ For examples, see A. AdkINS, supra note 5, at 251, 291; Vlastos, supra note 12. 
as an expression of a proto-Christianity) but as a way of conceiving of the self as an entity, naked and isolated. The social implications of these poetic modes of discourse are different from those of the logical refutations; they are less competitive and combative. And while the logical proofs and refutations have a kind of forcefulness that the myths and stories and speeches lack, their very form means that they can also be refuted, as the more poetic parts cannot be, or at least not in the same logical way.

In ways such as these the dialogue isolates and disorients the interlocutor (and hence the reader) by breaking down and reconstituting his language in ways that he cannot resist but does not wholly accept. The language thus remade has a special kind of richness and power that derives from the associative way that it is put together in the text: themes (such as the distinction between the "good" and the "pleasant," or between an "art" and a branch of "flattery") recur in ways that at first surprise the reader, but are then seen in a flash of understanding to be appropriate; patterns of use and association, not wholly translatable into English, are gradually established, such as the connection between the word for "punishment" in the conversation with Polus (kolazesthai) and the word for "licentious" in the conversation with Callicles ( $a-k o-$ lastos, un-punished). ${ }^{24}$

One particularly important network of such associations is built upon the word aischunomai (feel shame): this is the word used by Polus when he says that Gorgias was ashamed to admit that the good rhetorician did not need to know about justice (461b); by Callicles when he says that Polus was ashamed to admit that it was more aischron as well as more kakon to suffer injustice than to do it (482e); and by Socrates when he says that he would be ashamed not to have the power of preventing himself from doing wrong. (522d) Aischunomai is connected etymologically with aischron, and functionally with elenchomai and elenchos, the words for the kind of refutation achieved in dialectic, for these terms imply a kind of humiliating defeat. In the course of the dialogue the meaning of these terms is gradually transformed until aischunomai, which originally meant "to be ashamed before others," is internalized and comes to mean shame before oneself; the kind of shame before others that does remain, the refutation, is seen as benign, not hostile.

This set of changes is deeply connected to the fundamental

${ }^{24}$ Compare Plato, Gorgias at 476a (Polus) with id. at 507c (Callicles). 
ethical premise of the dialogue, the central importance of motive or intention in determining the condition of the self. The difference between rhetoric and dialectic is at heart one not of method but of aim. It is for this reason that Socrates is satisfied when Gorgias says that the good rhetorician must know and be able to teach justice, (459c-60a) for once that is granted all else that Socrates cares about will follow.

In the course of the dialogue agathon also undergoes a shift from the external to the internal. At one point, by a kind of analytic definition, the term is reduced to "what one chooses in fact" (475a-75e), but by the final paragraph it has become "that which one ought to choose or to be," ways to the ideas of order and health and friendship and community and separated from those of pain and pleasure. Consider, too, the question that arises when Callicles concedes that some pleasures are good and others are not (499b-99c): what is the standard of good to be? Socrates says that it takes an art to discern it and that all arts proceed by creating order and arrangement, not disorder and chaos (507a-08a); the good of the self and of the city will therefore be orderly (kosmion) in nature, not disorderly (akosmion) or unrestrained (akolaston). One may think that this is an incomplete statement, for the question still remains, what kind of order shall it be? ${ }^{26}$ But Socrates' concern has been not with that question, but with even larger ones: whether orderliness and restraint are good things, whether temperance and justice are to be valued as kalon and agathon, and so on. For him the central question is one of disposition or motivation: towards such things, or away from them? Likewise, the state from which Socrates seeks to preserve Callicles is one of division and discord within the self. ${ }^{27}$

In all of these ways the Gorgias offers its reader the experience of a mind dialectically reconstituting its language. The language so made is powerful, in a sense unanswerable, in large part because it seeks not to eliminate the variabilities, complexities, and inconsistencies of ordinary life and language, but to accept and clarify them. It is a language not merely of theory, but of poetry and literature as well. A language so made cannot be refuted by simply disproving one point or another; one must respond to it as a whole. Indeed the only true refutation would be the creation of a better alternative: this is what Callicles attempts but fails to do.

\footnotetext{
${ }^{25}$ See supra p. 860.

${ }^{26}$ See A. Adxins, supra note 5, at 273-74.

${ }^{27}$ See supra p. 862.
} 
It would be possible for us as readers simply to memorize the definitions, proofs, and propositions we find in the Gorgias, and make them part of our own intellectual equipment. This would be one way of learning to speak the language that is reconstituted here. But that is not what the text invites, or at least not the most important thing. For while it is true both that the final paragraph ${ }^{28}$ states propositions upon which the dialogue and Socrates rest and that these are offered to us as important truths, merely to memorize that paragraph without making it in a deep sense one's own would be of little value. What the dialogue really seeks to teach its reader is not how to speak its language but how to remake a language of his own; not to learn a particular set of questions and dialectical responses, to be repeated on other occasions, but-what Polus shows to be much harder than he had imagined ${ }^{29}$ - how to ask questions of one's own. To do this the reader must be a center of independent intellectual energy, a remaker of language and a composer of texts, and it is with helping him become these things that this text is ultimately concerned.

How does the Gorgias seek to do this? It works upon the reader rather as Socrates did upon his interlocutors, by isolating and disorienting him, by creating a conscious gap between self and language that makes the nature of both problematic in new ways. Like the interlocutor, the reader is broken out of his culture, out of the language and activities that normally serve to define him, and is prevented from defining himself by simply repeating established forms of speech or conduct. He is forced to function on his own: to take and define positions of his own creation, and to respond to those, valid and invalid, asserted by Socrates. In this way the dialogue defines and makes meaningful its central subject, the nature of the self and of community, for nothing less than this is at stake in the choice between "rhetoric" and "dialectic." The apparently distinct subjects of the dialogue-the nature of rhetoric and dialectic, of the happy and unhappy life, and of proper statesmanship-are really one after all.

\section{B. Self and Other: Dialectical Community}

As we have seen, the social character of rhetoric is directly contrasted with that of dialectic at every point. The goal of rhetoric, for example, is the power to persuade (peitho) others, to re- 
duce them to one's will. The goal of dialectic is the opposite of persuasion: to be instructed by being refuted (elenchomai), humiliated, corrected. This means that rhetoric naturally treats others as means to an end, while dialectic treats others as ends in themselves. Rhetoric persuades another not by refuting but by flattering him, by appealing to what pleases, rather than to what is best for him. If successful, it injures him. And it injures the persuader as well, for the flatterer, in the nature of things, becomes like the object of his flattery: he praises what the other praises, blames what he blames; in the fullest sense he comes to speak the other's language, and unless the other is a model of excellence, one becomes what one would not be, in one's very self, and that is the worst (the most kakon and aischron) thing of all.

Dialectic is wholly different both in method and in object. It proceeds not by making lengthy statements or exhibitions, but by questioning and answering in a one-to-one conversation. Its object is to engage each person at the deepest level, and for this it requires utter frankness of speech on each side, a kind of shamelessness in saying what one really thinks. One's concern is not with what people generally think but with what one thinks oneself and what the other thinks. This is not a competition to see who can reduce the other to his will, but a process of mutual discovery by mutual refutation. One accepts refutation gladly, for it reduces the divisions and disharmonies within the self, which Socrates tells Callicles are so much worse than those in a discordant orchestra or those between oneself and other people. (482b-82c) The object of it all is truth, and its method is friendship, the full recognition of the value of self and the other in a universe of two. One can see why the language of sexuality seems natural to describe these two relations: dialectic is a recognition of self and other, rhetoric a reification and seduction.

But, as the reader may have noticed, in the world presented in the Gorgias the ideal of dialectic is never achieved. Socrates' attempts to establish relations of this kind all end in failure. Gorgias concedes a central point, but without really understanding it. ${ }^{30}$ Polus is refuted, but only in the limited sense that he is beaten and cannot go on (478c-81b); he has not been brought to the position of independent understanding that dialectic requires. ${ }^{31}$ And Callicles,

so See supra pp. 855-56.

31 What might Polus do with his experience: remember some of Socrates' propositions, or some of his moves, and try to repeat them? Or will he merely remain disturbed in his relationship with his teacher, Gorgias, and with his language? Or perhaps not even that? 
having begun by boasting of his total frankness, at the end simply refuses to talk with Socrates in any honest way and leaves him alone, without an interlocutor, to make the speech in which he defends the way of life that may bring him death. ${ }^{32}$ In this sense, the Gorgias is the story of a failure of community, not of its success.

This failure suggests a way to define the object of Plato's text: to create in the real world with the reader the kind of dialectical relationship that Socrates is unable to establish with others in the world of the text. And observe how this textual community works: it has as its only object the education of the reader, making him in the Socratic sense more agathos, and it works only by his free cooperation and engagement. Its proofs and paradoxes operate, as I have suggested, to loosen the moorings that connect the reader to his language and culture: they break down his language so that he can say neither what he used to say, nor what Socrates offers him to say. He becomes a self outside his culture, faced with the fact of his own responsibility for making sense of what he hears and says, for becoming his own center of meaning and of language. The reader is led to see that what is at stake when he decides how to speak and what to say-whether to practice "rhetoric" or "dialectic"-is nothing less than "who he is" and what kind of community he will have with others.

There is a sense in which the text is more perfectly dialectical than Socrates attempts to be, for its interest in the welfare of another is more realistic, and in that sense, more complete and genuine. Whatever he says, Socrates cannot really hope to establish a dialectical relationship with Polus or Callicles, whereas Plato does seriously hope to establish such a community with his readers. The text is also a more perfect teacher. It offers its reader a set of experiences that teach him his responsibilities as a free person and give him some material with which to begin to discharge them. The ultimate value of the dialogue, reflected in the way it both teaches and respects its reader, is the value of the individual person. In this text Plato makes himself his reader's dialectical friend.

\section{Dialegctic, Rhetoric, and the Modern Lawyer: The Ideal Made REAL}

To the modern American lawyer the Gorgias presents both a puzzle and a threat. On the one hand, the description of dialectic I have given may remind the lawyer of his or her own legal educa- 
tion, making it seem more truly Socratic than it is sometimes given credit for being. Certainly the sense that one's relation with one's language is broken down, as one response after another is disproved, is familiar to the law student, as probably also is the sense that these "proofs" are sometimes deeply fallacious. On the other hand the object of legal education sometimes seems to be not the establishment of a new shared ground from which questions of justice and injustice can be talked about in a truer way, but mere rhetorical training, the mastery of the means of persuasion available in our legal culture.

Indeed, if what Socrates says about ancient rhetoric and its practitioners is true, how can it not be equally true of modern law and modern lawyers? For it is the function of the lawyer, like the rhetorician, to persuade about the just and the unjust, about the expedient and the inexpedient, and to do so not among people generally (or in the university), but among those who have power-in the courts, legislatures, and assemblies. Moreover, the lawyer always speaks in the service of someone else whose interests he represents and he accordingly says not what he believes to be true or right about an issue he addresses, but whatever will persuade his audience to act in furtherance of those interests. He is, it seems, the modern rhetorician in its purest form, and the law professor is his teacher-a modern Gorgias. To ask how the Gorgias speaks to the modern lawyer, and how he might respond, will thus shed light, I hope, in two directions: forward upon the ethical character of the modern practice of law, which I think is often misperceived, and backward upon the Gorgias itself, as we discover or invent responses on behalf of the modern lawyer to the challenge it presents him.

We do not have a real Socrates with real lawyers, and we must therefore imagine how their argument would go. The exercise is not wholly impossible, however, for the outline of the Socratic case is plain enough from what we have read, and one knows something of lawyers oneself. In what follows I will present such an imagined conversation, in which I try to show how two lawyers, of somewhat different types, might respond to the case made against rhetoric in the Gorgias. These two men, Euerges and Euphemes, ${ }^{33}$ are successful attorneys in a firm with a diverse general practice. They have agreed to talk with Socrates as they walk back and forth through a large city park on a spring afternoon. 
Socrates: What I really want to know is who you are and what you do. I know you are called a "lawyer," but what I want to know is this: what do you do in the world that makes you what you are?

Euerges: I would put it this way: I give advice to people who seek it from me about their legal rights and duties, and I represent them in legal proceedings.

Socrates: In whose interests are you acting when you do these things?

Euerges: In the interests of my clients, of course. And in the interest of the law as well, for in my work I help see to it that the law is obeyed and adhered to, and that legal institutions function as they are intended to. .

Socrates: Let us take the client first. How does what you do serve his interests?

Euerges: By increasing what can be called his power over the world: his range of choices for action, his liberty, and his wealth. Those are all good things and my clients show by their appreciation that they know this is true. I use the law to help them get what they want. I am their friend in the law.

Socrates: But is it always in someone's interest to increase what you call his "power"? I suppose you would agree that people sometimes use their "power" in ways that are self-destructive, and in such cases to increase their power is not a help, but an injury?

Euerges: That is a theoretical possibility, I suppose, but, as the world goes, not a real one. My clients are intelligent, practical people who know what they want and are satisfied by my efforts to help them get it. If what you mean is that it might in some way be better for one of my clients to do something else with his time and energy and money, to become a South Seas missionary, for example, or to write the novel he has always talked about, that is, I suppose, possibly so, though I do not often think about such things. I am not even sure what it would mean to say that such a course was "better" for one of my clients, since everyone is entitled to his own views on such personal matters. Anyway, who am I to make such a judgment about someone else, especially when I know so few of the relevant facts?

Socrates: But it remains true that you do not after all serve your client's interests, as you originally said, but instead what appear to him to be his interests, that is, his wants or desires. Isn't that right? And in what you have just said you do not deny this but seek to explain or justify it, by pointing to the supposed com- 
petence of your clients (and your own supposed incompetence) at deciding what is good for them, and to the allegedly uncertain character of that judgment, whoever makes it. Strictly speaking, then, it is true that you serve not your client's interests but his wishes or his wants?

Euerges: Strictly speaking, that is true.

Socrates: If so, you are in this respect no different from the keeper of one of those Pleasure Ranches they have out West, who sells his customers whatever they desire, however bad for them it might be: too much food and liquor and drugs, and every kind of sex. In both cases it is not the client's interests that are catered to but his desires, and in the case of the law the desire in question is more dangerous than any other, for it is the desire for power.

Euerges: This is nonsense! Don't you know that an important part of the practice of law is talking with one's client about the wisdom of one course of action over another, in a mutual attempt to determine what his true interests require? We are constantly teaching our clients that they cannot have everything they want and advising them to pursue what is more important to them and to forgo what is less important. We help them to discover their true interests and to shape their wants to suit those interests.

Socrates: If that is so, the present conversation can come to an end, for I have no differences with you, and we should begin on another subject: how do you do what you have just described? For nothing could be more wonderful than to discover a person who knows not only what is best for himself and for others, but also how to teach others what their true interests really are. But I imagine that not every lawyer would make such a claim and that many of those who did would mean by it nothing more than this: that they advised their clients how they could gratify their desires the most-as a really expert keeper of a Pleasure Ranch might do, telling his customers not to drink to incapacitation, or not to combine drug $A$ and drug $B$, and so on-but having no concern at all for their true interests. Shall I tell you what I would say to such a lawyer? If you permit me, I will make a speech to him, and you can tell me when I am done whether you and I are wrong, or he is.

Here is what I would say: by reason of your training and natural capacities you have what is commonly called a great power, the power of persuading those who have power of a different kind, political and economic power, to do what you wish them to do. Of course your power is not absolute, for there are limits to what even you can achieve. And properly speaking, this is not a true power unless it is exercised in your true interests, but it is a real force, as 
your record of success and the fees you receive demonstrate, and we can speak as others do and call it a "power" too, though putting it in quotation marks.

Your professional aim is to present your case, whatever its merits, so that those with control over economic and political forces will decide for your client, and you most succeed when you most prevail. You use your mind, as we used to say of the sophists, to make the weaker argument appear the stronger. Your goal in all of this is to get the most, first for your client, but ultimately for yourself, for what you do with your "power" of persuasion is to sell it, getting in exchange another "power," that of money. Of course neither the power of money nor the power of persuasion is a good thing of itself; that depends upon whether they are used to advance or injure one's interests, and that is no concern of yours, with respect to your client or apparently to yourself.

You say you are your client's friend, but you do not serve his interests; in truth you are not his friend, but his flatterer, which is to be his enemy. For your concern is not with his real interests, but with assisting him to attain whatever it is he may desire. If it should happen that what you do does advance his true interests and thus tends to make him happy rather than unhappy, that still does not make you his friend, because for you that result is accidental, of no interest or consequence. Not having been your object it can be no ground for your satisfaction. Likewise, you are no friend to the law, for you will always say that justice requires whatever it is that your client wishes, and you use all your skill and art to make it seem that this is so.

In all of this you are least of all friend to yourself, for in return for money that you cannot take the time to learn how to spend, you give yourself the mind and character of one who does these things. You never ask yourself in a serious way what fairness and justice require in a particular case for to do that would not leave time for what you do. In fact you incapacitate yourself for the pursuit of such a question by giving yourself the mind of the casemaker and brief-writer, of one who looks ceaselessly for the characterization, the turn of phrase, or the line of argument, that will make your client's case, however weak, seem the stronger. To persuade those whom you must persuade you devote yourself with the attention of a lover to the ways in which they can be pleased, to the tricks of voice and manner and tone, to the kinds of argument, that will persuade this jury or that judge, this tax official or that fellow lawyer.

The art of rhetoric is in fact the art of ministration to the 
pleasures of another, really a species of prostitution. As the sexual responses and energies of a prostitute are debased and debasing by the way they are employed, so also are your intellectual energies and responses, your ways of seeing things and describing them, your ways of making appeals and claims and arguments, the very workings of your mind and the feelings of your heart. When you represent an unjust client you are in the position of actually wanting an unjust result. And what do you get in return? A prostitute's pay. Like other flatterers you tend to become like the object of your flattery, but since you have so many and various objects of attention what you really give yourself is the character of none but that of the chameleon, who appears to be whatever suits the moment. In your trade you lose yourself.

Well, Euerges, what do you say of my speech? Is it fair or not? I speak not of you, of course, but of those lawyers who serve a client's wants rather than his interests.

Euerges: Of course it is not fair, Socrates, but idiotic. What you do not understand is that the lawyer does not operate alone, but as a part of a community of lawyers and judges, as one component in a larger system. Since the aim of that system is to do justice, it is justice that the lawyer ultimately serves, even such a one as you describe. Of course he wants to make a good living, and of course he wants his client to prevail-that is part of his function in the system-but above these wants is a larger intention, that of serving justice itself. And our adversarial, individualistic, and pluralistic system, although undoubtedly imperfect, has been shown by experience to be the best system for achieving justice yet devised in our imperfect world.

Socrates: I am full of questions about the remarkable claim you have just made-How do you know that this system produces justice? What kind of justice is it? What kind of experience teaches you this? and so on-but I will put these questions aside for the moment to continue with what we were talking about. For even if it were agreed that the "system" does what you claim, that would only justify the sacrifice of character made by the lawyer, not deny it. He would still subject himself to the same deformities of mind and feeling; the only difference would be that he could say that it was all in a good cause, as a soldier might say who died a horrible death for his country. But the self-inflicted deformity would still be there.

Suppose, for example, that you represented a white man in a dispute with a black man, that your client was in the right, and that the judge and jury who were to hear the case were white rac- 
ists. Your appeals to their bigotry, whether explicit or implicit, whether expressed in words or silence or shrugs or looks or tones of voice, would be in the "cause of justice" in the sense that you mean, but they would still deform both you and your audience, polluting both the process and the community. Argument of this kind can never be truly in the cause of justice, as argument based on falsity can never be in the cause of truth, yet your duty, as you call it, requires you to make arguments that are unjust and false, at least in the sense that they do not represent what you believe justice and truth to require. And you must do this not merely where your client is right, as in the example I have given, but where he is wrong as well.

Euerges: Socrates, you are speaking as if we had made no progress at all since the fifth century, as if the modern lawyer really were like the ancient rhetorician and subject to no constraints of law and custom, indeed, as if there were no substance to the rules he applies and follows and argues about. Actually, doing lawyer's work is a discipline in responsibility and truth. In the first place, there are ethical limits upon the way he can argue: he may not misrepresent either the facts of the case or the law, and he may make only those appeals legitimized by our system. Appeals to bigotry and the like, then, are out. And while there is of course some leeway in the interpretation of legal doctrines, they are by no means infinitely pliable-indeed much of our time is spent applying plain rules with plain effects. This is one way the law is made real in the world. And although the rules that we apply are, like everything else in the world, imperfect, they are rooted in a democratic form of government; having the assent of the people, they are more likely to be just than any other rules. There is a sense, indeed, in which they are by definition just, for they are the product of the most just of all constitutions.

Socrates: But all this, even if I accept it, merely confines and limits the evil, it does not deny it. Your claim essentially is that you are a rhetorician in a good cause, or with good effects, but you remain a rhetorician, with all that that means. Suppose a similar claim were made, for example, by a historian, who said that he did not try to write what he thought was true, but what would most favor a particular person or group or party: every statement of fact, every term of evaluation, was chosen and placed to serve such ends. Suppose further that he were to justify this practice by saying that it was what everyone does, and that experience has shown that what he calls "advocate's history"-and what you and I would call propaganda-produces a more complete and accurate version 
of the truth than any other kind. Would you have respect for such a historian, and for such history, or contempt? W.ould you want to be such a historian or want your child to become one? And it would not matter much if there were some ethical limits on the degree to which one could shade things, for the historian would still be a shader of truth, a propagandist, not a historian.

One cannot be a propagandist in the service of truth or an advocate in the service of justice, for the character and the motives are wrong. And character and motive are for these purposes everything, for "truth" and "justice" are not abstract absolutes, to be attained or not in materially measurable ways; these are words that define shared motives out of which a community and a culture can be built and a character made for the individual and his world. They express an attitude, imply a process, and promise a community.

The true historian, who tells the truth as well as he can, exposes himself to refutation: if he is shown to be wrong, it is he who is wrong and it is he who learns from the refutation. He has a self in the world that can teach and can learn. But the lawyer, or such a rhetorical historian as I describe, can never be refuted, but only beaten. He has no self in a world of others.

And is not something like this true even of you, Euerges, when you move from working out with your clients what their true interests require to representing their interests at law? Then you, too, must speak the legal language according to legal conventions: you become an accomplished shader of the truth, and give yourself the facile and shifting mind of the lawyer. Or do you simply say to other lawyers and to judges what you honestly believe that justice requires?

Euphemes: Of course he doesn't do that, Socrates, and neither do I. And I should also say that unlike Euerges I do not spend time with my clients trying to determine what you at least would call their true interests. Of course I do go over and over their problems with them, trying to help them figure out what they want to do, and I will suggest considerations and questions and facts they seem to have left out. But their decision, if it is legal, is final with me. The most I do is to help them organize their affairs in ways that will suit them in the long as well as the short run. I also have to say that I have no faith that our system of justice has been proven by experience to be the best possible one. I'm not sure what Euerges means when he speaks of our "system" or that justice is its "end," and I don't know whose experience he is talking about, whom it teaches, how it teaches, or what it teaches. As for the rules 
and principles of law that we apply and argue about, I certainly do not think they are the perfection of justice: some of them seem to be right, others pointless or wasteful, some of them seriously evil. Nor do I think that their origins in our version of a democratic system of government entitle them to automatic veneration. Euerges justifies the activities of his life not in their own terms but by claiming that they are part of a larger system, which has been shown by experience to be the best possible one. But I do not share his faith in the perfection of our legal system, whether it is measured by results achieved or standards applied, and I dare say no one else does either who is not forced to such a position by his choice of profession.

Moreover, I know I do not represent only the noble and the good. Most of my clients are good enough in an ordinary way, but basically unthinking and rather selfish; some are in my view pretty despicable people engaged in pretty despicable enterprises. I help them not only when I think they are in the right, but when I think they are in the wrong, so long as it is not legally wrong or so morally wrong as to be intolerable. In many of the cases I have litigated I am inclined to believe that justice was on the other side, though I have not really asked myself that question in a disciplined way.

In our arguments, whether made to judge and jury at trial or to other lawyers in negotiation, we do not say what we believe justice requires but whatever we think will persuade our audience, subject only to the ethical constraints already mentioned by Euerges. And I have to say that while these constraints to some degree civilize the process, they do not change its fundamental nature. Indeed they permit, and may even be thought to require, a lawyer to discredit witnesses whom he knows to be telling the truth and to suggest false inferences that may plausibly be drawn from true facts, and they give at least some play to motives of bigotry and prejudice of various kinds.

I said before that I do not spend time with my clients trying to determine their true interests, and I acknowledge that sometimes they, and others, are injured by the increase in power they get through my successes. Moreover, I agree that this is important, for it is a question of who they are and who they become. I also think it is important what kind of person I am and what sort of community I help to constitute, and I know that to make myself a lawyer is to give myself a mind of a certain character or cast, and that this is in large measure determined by what happens in argument. But I would describe these things somewhat differently from you and 
Euerges.

Notwithstanding what you may take to be the implications of what I have just said, I do not think that to practice law is to deform the self. In fact, the character of the trustworthy lawyer seems to me thoroughly admirable, difficult to attain, and, what may surprise you most, to be acquired not in spite of his daily work in the law, but in large measure because of it, by virtue of its discipline and experience. Of course there are really bad people in the law, as in every profession, and perhaps very few people, or even none, fully attain the possibilities I mean to point to with the phrase "trustworthy lawyer." But my point, like yours, has to do with the tendency of the practice of the profession, and I think that its tendency is not to injure but to improve the character, and that it offers possibilities in this respect that most other ways of living lack. I should add that I do not think that this tendency is much affected by the nature of one's clientele, nor even by the substantive rules with which one must deal, but that it is greatly affected by the nature of the ethical community that one establishes with other lawyers and judges.

I think you and Euerges have simply misunderstood the enterprise in which lawyers are engaged. I would put it this way: in our professional lives we lawyers preserve and improve a language of description, value, and reason-a culture of argument-without which it would be impossible even to ask the questions that you think are most important, questions about the nature of justice in general or about what is required in a particular case. This is because "doing justice," "arguing about justice," and "deciding what justice requires" are never wholly abstract activities, but are always culturally conditioned. They are ways of doing things with preexisting materials and expectations, just as "doing music" and "doing architecture" are; what we lawyers do is to maintain the materials essential to these cultural activities and the conventions and understandings that make them possible.

The first essential resource for the activity of talking about what justice requires is a language in which the social world can be constituted and described, so that a story can be told and an issue stated. At the simplest level we need words to describe the various parties, their situations, and their motives before we can even state a question about what justice requires in a particular case. Similarly, we need procedures and understandings to regulate our talk, such as conventions about representation, the order of speech in the court or assembly, and the like. And we need as well a preexisting language of right and wrong, of expectation and prohibi- 
tion-rules and maxims and proverbs and stories, and, perhaps, cases-before we can go to work. Let me try to make this point by using an example familiar to you, Socrates. If I remember my undergraduate reading correctly, the Iliad begins with a dispute that arises when Agamemnon is forced to give up his prize girl to her father, the priest of Apollo, after Agamemnon originally refused the ransom request for her. Achilles and Agamemnon divide over whether Agamemnon should bear the loss alone, or whether the community of warriors should in some way make it up to him. Now one could not accurately state the question presented by this situation, let alone think about what right and justice require here, without words to describe the prize girl, her father the priest, the ransom, and the warriors and their chief. And not just any words will do-think how weakly the English words given above permit one to understand these actors and events; we need the Homeric words themselves, the language that defines the social world and the values that give particular meaning to the dispute. Only in the language of this culture can argument proceed about the issue of justice that has arisen within it.

You yourself, Socrates, show that you know that we need a language of social fact and value, for you invite your auditors not to a languageless looking at the eternal essence of justice, but to a taking-apart and putting-together of the materials of existing culture, a reconstitution of language in a community of two to which all your loyalties extend. What we lawyers do is both similar and different: in working on our cases we constantly test our language against new facts and circumstances, against its own hidden or overt tensions, against common experience and new formulations, and in this sense can be said repeatedly to take it apart and put it together again. But our loyalties extend beyond the community of individuals with whom we talk to our legal world, indeed to our culture as a whole.

The object of our work is not to make a new language good only for two interlocutors, as yours is, but to leave the language we have remade in a condition fit for use by others. It is in fact our method of argument, which you deplore, that enables us to do this, for as we articulate our points of disagreement in a particular case, at the same time we necessarily perform an agreement with the rest of the language in which our disagreement is stated and our arguments framed. In order to assert our differences on some points, that is, we must acquiesce in the language we use to make these differences intelligible and meaningful. The effect of this is to convert the raw human materials of greed and fear and the de- 
sire for power, and the like, into questions presented in the language that we maintain. Our work is what makes possible the connections between one case and another, between past and present, that constitute this branch of our civilization.

I say that we not only maintain but improve our language, and in one sense $I$ am sure $I$ am right. For this process ensures, as nothing else could, that congruence between the terms and assumptions of our language and the conditions of social and natural reality that is essential to the survival of a language of justice and the culture it enacts. But we also improve it in another way, I think, for the law as I describe it becomes a repository of shared experiences, a set of experiments and trials and failures, which are by the law made intelligible and shareable. This is a culture of experience and experiment; it is a way of giving experience to ourselves, individually and collectively, the experience of making and remaking language under pressure. For in the law, our language of facts and law is constantly being tested against the real world, against common sentiment, against cases and argument, and remade in light of what is discovered. This means that the law is a way in which the community defines itself, not once and for all, but over and over, and in the process it educates itself about its own character and the nature of the world. The limits of our minds and imaginations are reached and tested, and a new step taken. That is what the law is about. The lawyer is not a dialectician, but neither is a poet or an architect, and as is true of them, the meaning and pleasure of the lawyer's life arises from his participation in making and remaking a world of shared significance.

What this view of the law means about the ethics of legal argument is this. First, while I am in a sense "insincere" when I say to a judge, for example, that "justice requires" or the "law requires" such and such result, this insincerity is a highly artificial one, for no one is deceived by it. No one in the courtroom would be surprised to learn that this is a form of argument and not a statement of personal beliefs. But at the same time I am implicitly saying something else, with respect to which $I$ am by any standard being sincere: that the argument I make is the best case that my capacities and resources permit me to make on this side of the case. This is a statement made by performance rather than in explicit conceptual terms, and it is a statement not about the nature of "justice," but about the nature of the resources our legal culture affords for defending or attacking a particular result. But it is a statement honestly made.

In making this statement the lawyer's audience is the judge, 
and we serve him directly not by telling him what we actually think he ought to do, but by showing him something about the nature of his own situation in our culture. Together, the arguments of the two lawyers define the boundaries within which the judge operates by showing what even these parties, opposed as they are, must agree to, and they tell him what topics the culture requires him to face and deal with. Our arguments also provide him with a testing ground for his own thoughts. As the judge thinks through the case, at first.inclined one way, then the other, he will take up the opposing arguments, oral or written, to learn what he has not yet dealt with in his own thinking and what he has. The briefs and arguments help him think his way into a problem and provide a kind of check list to tell him when he has thought all the way through it. And there is room for art and invention, too. We tell the judge truthfully not that we think a judgment for our client is the best result-that conclusion is determined by our role-but that the formulations we offer are the best version of our discourse in support of this result that we can find or make.

This kind of rhetoric, despite what you claim, leads to a kind of knowledge and not to mere belief-knowledge about the ways in which the materials of persuasion in our culture can be mobilized. The "trustworthy" lawyer of whom I speak is one who can be trusted to perform this task honestly and intelligently, making the best case he can in light of what can most persuasively and fairly be said on the other side. It is the incompetent or sleazy lawyer who misrepresents or fudges the nature of the material, and his work is of little assistance to anyone. Though on one occasion or another he may prevail through the confusion he creates, over the long run he will fail, in part because those to whom he speaks will see what he is doing. The competent lawyer is by nature trustworthy in the sense I describe, for trustworthiness is essential to his professional standing and success, not only in the long run but in the short run too. It is not too much to say that in his presentation of the best case that can be made in the circumstances the good lawyer loves to tell the truth.

I have said that the judge is our ultimate audience, and this is true even in negotiating transactions and planning a client's affairs, for the judge is the final authority to whom recourse may ultimately be taken. And although it is true, as you say, that the persuader becomes like the object of his persuasion, it is our practice to address the judge not as the bundle of biases and feelings and predispositions and ideas that he in some sense is, but as if he were an ideal judge. It is what the best judge we can imagine would 
want to hear and know that we try to provide. (The practice of speaking to the best in the judge we address is in fact enforced by considerations of prudence, for to be caught addressing him any other way is obviously very dangerous indeed.) Thus while at first there may seem to be a huge difference between the justice-loving judge and the advocate who merely wants his client to win, in fact the mind of the advocate is deeply formed by his own conception of what the best judge would be and what he would want to know: it is to his own ideal that he gives what you call the attentions of a lover. To do this is not to injure but to improve the self; it is very close to what you mean, Socrates, when you speak of your devotion to philosophy.

This is a way of justifying the lawyer's life by understanding the process of which his activities form a part, as Euerges' was too. But unlike his justification, mine does not depend upon a faith that the substantive rules we work with are the best of all possible rules, or even that they are substantially just. Nor does it claim that our particular procedures for inquiring about and deciding questions of justice are most likely to lead to results that are just. In fact, the justification I advance would support the activity of being a lawyer in almost any legal system, however unjust its rules might be on the merits, for the lawyer's task will always be to make the best case he can out of the materials of his culture in addressing an ideal judge. By its very nature, this is to improve his materials, both by ensuring their congruence with the world of facts outside the law and by moving them toward greater coherence, fairness, and the like.

Socrates: So it may be, Euphemes, but have you not simply substituted one faith for another? Euerges has a faith that the present legal system, as measured by its rules and results, is the best one possible; you have a faith in your capacity to make arguments the tendencies of which will always be to improve rather than to damage the culture you have inherited. But upon what does your faith rest? May it not happen, for example, that your particular audience, say your judge, will be persuadable by distinctions and appeals that are, in your view, not better but worse? And in such a case you will make those arguments, for they are what will work, and in doing so you will contribute not to the improvement but to the degeneration of the discourse. Is this not so?

As I understand your claim it is like that of an artist. You are like the musical composer who makes the best kind of music that can be made, or that he can make, out of the cultural and physical materials available to him. By "materials" I mean the musical in- 
struments on the one hand and the expectations that people bring to musical performance on the other, for it is with both of these that the composer must work. Indeed, every artist makes his artifact partly out of the materials of nature-stones, bricks, sounds-and partly out of the materials of culture-those expectations that define his audience and enable him to surprise, to please, and to instruct them. These expectations form a kind of language through which, and only through which, his work can be intelligible. We do not praise or blame the artist for the nature of his materials, of either kind, but only for what he does with them, and the same can be said of the lawyer, and perhaps of the judge as well.

Thus the musical artist-and the same is true of the architect as well, and perhaps of the painter or dramatist-does not collapse into his culture, as Euerges did, when he appealed to the supposed perfection of the system and the respect due to the products of a democratic society, and so forth, but in some measure breaks himself out of his culture, distancing himself from it by claiming to maintain and improve it. The artist, and according to you the lawyer, thus assimilates himself not to the culture as it is, but to his own ideal version of it, and to the processes by which he attempts to make and remake it in that image.

But how can this be so? Where the conventions of the art are not beautiful but ugly, will the work of the artist not be ugly too? And where do the standards by which he establishes his ideal come from? Are they not also formed by the musical or legal culture itself, with all of its defects? Either as a lawyer or musician, then, how can you have any confidence that the changes you make are true improvements, that the ideal to which you assimilate yourself is a proper one? The questions of beauty and justice are in the end the most important ones, and for them rhetoric is plainly useless: only dialectic will suffice.

Euphemes: You state my claim well enough, Socrates, but you evaluate it wrongly, in part because you evaluate dialectic itself wrongly. Of course I do not "know" that my arguments are improvements or that my conception of the ideal judge is best, and of course these are important questions. But you do not know these things either, and what we are really talking about is how such questions ought to be addressed, which is itself another version of the question we have been asking from the beginning: how ought we to lead our lives? The first claim I have been making is not that I do the best possible work with my materials-that is the kind of claim Euerges makes for the "system"-but that this is what I 
strive for. It is a question of aim and motive, as is proper when the issue is how we lead our lives.

I also make a second claim about our method, especially as compared with dialectic. For the questions you have asked me-whether the particular argument improves the culture, or the particular conception of the ideal judge is a proper one-dialectic is valueless, because in dialectic you confine your responsibilities to yourself and one other; you remake your language and community on the scale of two. For these questions, dialectic can produce no answer at all, because the questions themselves presuppose a larger world, in which alone they can have meaning. The answers must be good not only for the two of us, but for our whole community, for the others who act in our universe and speak our language. To say, as you do, that it is never good to have any relationship with any person that has any object other than discovering what is ultimately good for each of those two would in fact mean the end of culture; the lawyer is one whose aim it is to maintain and improve the culture that makes possible a larger life, in a larger world.

Socrates: Let us put aside for the moment what you say about dialectic, for you still have not answered my question about what you yourself do. How can you claim to be constantly improving your discourse and culture? Suppose for example that in a particular legal system the ideals to which appeals can be made, the materials for the "best case," are vicious ones? You will then move the discourse in the direction of vicious ideals rather than just ones, will you not? And once you concede that this is so, you will have to tell me how you can possibly know that your own culture is not one of the vicious ones. When you do, you will engage in dialectic, not rhetoric.

Euphemes: To start with, I do have to say that I am not sure that it is a good thing to be a lawyer in any imaginable culture. There is always the possibility that a culture is so horrible that it should be destroyed rather than improved, that one must become an enemy of the political system in order to be a friend to the nation. But I do mean to suggest how that question ought to be thought about, and I think my answer may lead as well to a response to your question about standards and ideals.

In deciding whether we ought to be lawyers in a particular legal culture, we ought to ask not whether there is injustice there, or even serious injustice, for these will be part of any culture. Instead, we should ask about the materials for argument the culture makes available. Does this culture afford the materials with which one can appeal to its better side, establishing and reinforcing standards 
and values that are incompatible with its evils, and thus counteract them? Think for example of the lawyer in South Africa and the importance of his continually affirming the aspects of that tradition that honor individual autonomy and liberty, that respect each person as an individual, and that are thus wholly incompatible with the country's racist laws. Or think of a lawyer in a Soviet satellite state affirming the principles of legality with which the Party sometimes, but not always, interferes. Or of a lawyer in America appealing to our traditional ideal of equality to correct the hideous inequalities, especially racial inequalities, with which we live. The question for the lawyer is not, does my system achieve justice, but rather, does it afford materials for idealization which, when mobilized by lawyers on both sides of a case, will tend to improve the culture itself? This view corresponds with the common feeling that it is of great importance to have conscientious and high-minded lawyers in regimes that are illegal or corrupt.

Will the answer ever be that the culture must be abandoned? I am not sure it will, for the very act of speaking about justice in a particular case on behalf of one of the parties always affirms the possibility of justice under law, and it necessarily entails, even if it also frustrates, the process of idealization of which I speak. Such speech also makes real an essential equality between the speakers, if only for a moment; and it affirms the practice of reasoned judgment, and that entails certain ethical consequences as well. It may indeed be that it is good to be a lawyer whenever one can speak for another and sincerely make the best case that one's materials afford.

This is also, as you can see, a partial answer to your question about my faith in the improvements to be worked by law. Some elements of what we mean by justice are not complex but simple, and the practice of law as I have defined it continually affirms these: the values of equality, of reason, and of the very idea of appealing to right and justice against brute power. I have described the process of idealization that is involved in legal argument, and I think it is a part of all legal argument: if an argument lacked that quality, it would no longer be legal, but purely instrumental or expedient. While it is true that some of the particular ideals appealed to may be undesirable or ugly, it is better that the practice itself should exist than that it should not. Indeed, as I said before, only if it does exist can one seriously ask the question that ultimately concerns you, namely, what ideals we ought to pursue.

All this assumes, as you point out, that the lawyer has standards and ideals by which to judge the possibilities for expression 
and action that a particular culture makes available to him. This returns us to the questions, where these standards and ideals come from, how they are to be tested and explained and defended, and so on.

It is implicit in what I have said that at a certain level these things are easy enough, for some injustices are plain and brutal enough to be self-evident to anyone. At this level what we mean by justice is a community that maintains the minimal standards of the rule of law. It is better to have a hearing than no hearing, better to have a tribunal that claims obedience to authorities external to its will than no such tribunal, and so on. As for more complicated issues of justice-the right result in a particular case, for example, or in a particular class of cases, or the proper standards of distributive justice-the question for both of us is not whose answers are right, for neither of us has answers, but how to go about living and thinking in the conditions of uncertainty in which we find ourselves. With respect to these questions, what we mean by justice is a community of a certain sort, a community that proceeds to examine and talk about and decide these questions in a promising way. What really divides us is how to judge the lawyer's way of doing these things.

Here I must return to my earlier claims that the activity of talking about justice requires the existence of a language in which factual and moral problems can be coherently and meaningfully stated and that what we lawyers do is to maintain that language in a condition in which it can be used for those purposes by ourselves and others.

What do I mean by a "condition in which it can be used"? To start with, a language of justice must have within it room for claims both of expediency or self-interest on the one hand, and of justice or virtue on the other, if it is to have a life in the world. You show that you know this when you show that Callicles' attempts to strip his value words of all but their selfish meanings are doomed to failure, leading to intolerable intellectual and moral confusion. The attempt to use a purely pragmatic language, and to reject the limits imposed by a language of justice, destroys one's capacity to reason sensibly and to function coherently. Indeed it destroys the very idea of a self upon which the language of selfishness itself depends. [ ${ }^{[4]}$

But the converse of this is also true: to strip a language of

s4 For an elaboration of this point, see chapter 3 of my forthcoming book, When Words Lose Their Meaning, supra note $\dagger$. 
justice of its congruence with actual facts and sentiments, with the felt needs of those who use it, is to strip it of any force in the world. And this is what you do. You find an intolerable conflict within the central value terms of your own Greek language (agathos, kalos, and the like) and seek to strip them of those elements of meaning that reflect the competitive or success-oriented culture in which they had their origins. But when you do that you make a language that is "paradoxical," impossible for others to speak.

The function of the law is to maintain a language that keeps alive this very tension between fact and ideal, expediency and justice, self and other; this tension is in fact essential to the practice of talking about what justice requires. You can see this tension in my own defense of law: when I say that the lawyer makes the "best case" that can be made in the circumstances, does that mean the case that is most persuasive or most just? You would draw a sharp line between them; I would not say that they are the same, but I would say that the answer to that question is always, or almost always, unclear. For to be the "most just" argument it must be a workable one; to be workable, it must be just, at least in the sense that it must maintain the possibility, essential to the existence of self and community, of appealing to ideals that limit the will.

In other words, it is the object of our work to ensure that the language of the law has both the congruence with reality and the element of aspiration that are together essential to any meaningful talk about what justice requires in an actual community. As for the improving character of a particular argument, that is a matter that must be examined in the context of a particular discourse and a particular case; what we do is establish the conditions and means for that examination. We cannot guarantee the results, but no one can do that. What we can do is justify the practices that make possible thought about justice of a kind that is at once realistic and idealistic.

In the process that I describe the law converts the raw materials of human nature and conflict into another form of life and language, into argument about justice. This conversion is in fact what marks us as human beings, for it is this above all upon which the life of the polis, of human community itself, depends. Indeed, what is true of the city is true of the self as well: both for the lawyer and for his client, the passions of ambition and conquest and competition are put to work in the service of a larger enterprise, the practice of arguing about what justice requires, without which we would have no city at all, no community, and no philosophy. 
The mind the lawyer gives himself is one that loves this process of conversion and translation: the making of a certain kind of conversation and the maintenance of the conditions upon which it can proceed. You should understand the pleasure and meaning of such a life, Socrates, if anyone can.

Socrates: But even if all that you say is true, Euphemes, none of it justifies what you do when you present evidence and argue about the facts, as opposed to engaging in the sort of argument about the law that you have been discussing. Surely making the "best case" on the facts has a different ethical meaning from making the best case that the resources of the law permit you to make on a question of standards or norms. How can you possibly call yourself a friend to the jury when you cross-examine with great skill a witness you know to be telling the truth, or ask them to draw plausible but erroneous inferences from true facts? Whatever may be the case with respect to the judge, then, with respect to the jury you are a pure rhetorician with all that that means: the flattering pleaser and deceiver. Is that not so?

Euphemes: Certainly not in the way you claim, Socrates. It is true that there are important and problematic differences between argument about the law and argument about facts, and I will say something in a moment both about the nature of these difficulties and about what it means to address them correctly. But first I need to correct your assumption that the lawyer will-that he professionally should-do whatever the law permits him to do on behalf of his client. Although some lawyers of course take that attitude, not all do so, and you and I have agreed that our subject is not the ethical quality of the majority of those who actually engage in the practice of law (though that is an interesting question) but the ethical possibilities of the profession.

Let us take the cross-examination of the truthful witness. To some degree what I said about judicial argument also obtains here, for the jury knows that each lawyer is trying to present his case in its strongest light, and the combined efforts of the lawyers do in fact aid the jury in its decision of the case as a whole, for they now know the most that can legitimately be claimed on each side. And in both cases there is a similar duty not to mischaracterize the law or the facts. But you are quite right that there is a critical difference between the two kinds of argument as well, for the judge or other lawyer can effectively check and challenge your characterizations of law, since all have access to the same material, but with respect to the facts some of what you know is simply not available to the other side. This means that the lawyer must indeed take 
special care in making factual claims, and many lawyers do so. Although it is true that the law would permit the savage cross-examination of a truth-telling witness, that does not mean that every lawyer would do it, or should do it.

Socrates: How can that be? Do not your conventions of argument require you to do for your client whatever the law permits you to do?

Euphemes: No, of course not, that is what I am trying to tell you. Although most lawyers would be reluctant to admit it even to themselves, different lawyers would respond quite differently to the cross-examination question: some would cross-examine as rigorously as they could, others more softly, some might in fact not cross-examine at all but concede the factual point being made.

Socrates: But how could a lawyer justify to his client any course of action other than the first?

Euphemes: The process of justification would begin with the beginning of their relationship, when the lawyer let the client know that although the client had employed his professional skill he had not obtained the right to dictate how that skill should be exercised. This can be made clear by explicit statement, something like this: "If you want my services you must understand that I observe what I regard as the decencies of life in my relations to other lawyers and parties and witnesses. I will not treat you shabbily; do not expect me to treat others so. I will not be your mouthpiece, but your lawyer." That is, of course, rather pompous, and in many contexts a lawyer would feel that he could establish the essential point implicitly rather than explicitly-by the way he dealt with the client and spoke about the other lawyer, the other party, and the process itself. This kind of statement is not only possible, it is far more common than most people, including most lawyers, are actually aware: think how often a lawyer refuses to take advantage of a procedural default, for example, or how often, at least in certain branches of the practice-divorce comes particularly to mind-the lawyers on both sides refuse, despite great pressure from their clients, to engage in childish and vindictive litigation.

If challenged, the lawyer could explain his position on two grounds. The first, suggested above, is contractual: this is what I offer you, and you have the right to reject it and go elsewhere. The second is more difficult to talk about, but if anything even more important; it is ethical in the fullest sense of the term, and also from another point of view strategic. The lawyer might say something like this:

In the next several months I will repeatedly be speaking on 
your behalf to a wide range of audiences: the other lawyer, the judge, the jury, witnesses, other officials, and so on. I want these audiences to take seriously what I have to say. I am not a chameleon or an actor but a single person, and my capacity to ask them to listen to me in the way I want them to, on the merits of the questions I discuss, is in large part a function of my sense of myself. If I were habitually sleazy and manipulative, signs of that would appear and make me less effective as a speaker for you; if I were habitually ethical but occasionally sleazy, I am sure that my discomfort would be less than completely hidden. I can hardly exaggerate the importance of what I am saying: what the Greeks called the "ethos" or character of the speaker is among the most powerful sources of persuasion. In any case in which I act, my own sense that I am speaking properly, asking for what I am entitled to ask for, functioning out of a sense of fairness, is essential to my ethos and therefore to my success. And for success in two ways: not only in the material sense of gaining so many dollars by settlement or trial, but in the much larger sense of helping you to give this difficulty a meaning that is most valuable and appropriate to you.

Let me give you a couple of examples of what such a lawyer would mean. Often a particular dispute is one of a series of matters with respect to which the parties must deal with one another; in such cases proper management of one dispute will lead to quicker and easier resolution of others, and to the establishment of relations outside the adversarial context that are of real value, economic and otherwise. This is in fact the case whenever there are continuing relations, by reason of commercial connection, common children, or even because the parties simply live in the same community.

And even when one puts such considerations aside there is the question of the meaning of the result in the particular case for this client. What kind of victory does he really want? Here it is a great mistake to assume, as many people do, that clients naturally want victory at any cost, including that of unscrupulous behavior from their lawyers. Some do, of course, no doubt about it, but others realize that such an attitude is childish, impractical, and inconsistent with their basic sense of themselves. Many clients in fact want what they are entitled to and no more, and welcome the opportunity to deal with a lawyer who respects the decencies of life, as they themselves do. And they know in addition that the lawyer who is a shyster to others will often be a shyster to his client. They 
know that they can have little confidence in the judgment, knowledge, or skills of such a person.

All this, of course, does not answer the next question, which is how one decides what the decencies of professional life are and what practices are beneath them. On such questions categorical rules are of little help, and they must be thought through on the merits each time, or rather, since they arise continually, in surprising ways, and without notice, they must be instinctively responded to by the character that the lawyer has gradually given himself over time by his habits of ethical reflection and action.

My point is not to make the ethical dilemmas of the lawyer's life seem to disappear, but to establish that the lawyer is free to address them as true ethical issues for which he is responsible. Indeed, so far am I from denying the intractable difficulties of the lawyer's ethical life, that I would say that they are an important merit of it. Every day the lawyer faces questions of right and wrong that have no ready answer, no authoritative resolution, and this means that his professional life offers the opportunity for the building of a character that less problematic lives would lack.

It is true that in our relations with our clients we do fall short of the standard you would have us meet, in that we do not engage our clients in a dialectical investigation of what their best interests really require; in a sense we use them as the material of our art. But it is a corollary to what I have just said about the lawyer's ethical responsibilities that there are important senses in which this relationship, at least in its ideal form, is one of friendship, for it constantly presents the questions, for both of us, of how we should behave and who we should be; it involves mutual education and respect and is based upon honesty. As Euerges said, in leaving certain questions of choice to the client, the lawyer respects his autonomy; likewise, in reserving some to himself the lawyer insists upon his own autonomy, and this reservation is a valuable form of teaching. And the lawyer is constantly forcing upon the client new understandings of the nature of the world in which he lives and of his situation within it, either showing him the limits that reality places upon his desires or expanding his sense of what is possible, and he is himself always learning about these things too. On these matters everyone needs continual teaching. ${ }^{35}$ And any lawyer will

as The fact that the lawyer finds himself taking now one side, now another, without much regard for his personal predisposition is in fact an important source of education for him. It teaches him how much can be said for positions with which he is originally inclined to disagree. For this reason it is a great mistake to think, as some do, that the law professor 
tell you that compared with at least some of his clients, his role is to insist upon the truth, upon the facts that cannot be wished away. The lawyer is not only a fiction-maker, but a truth-respecter.

And one other thing: the good lawyer is faithful to the obligations he has assumed, to the client and to the law, and there is at once a kind of virtue and a kind of education in that. When he gives advice to his client, makes an argument to the jury, or drafts an instrument, he is engaged in making the world in which others live, and at every moment he is subject to obligations to others and to the law. His advice must be based upon a fair and accurate assessment of a situation; his argument must be punctiliously truthful in every statement of fact; his drafting must meet the needs of those whose life it will affect. A lawyer's life is a constant assumption of responsibility to others, and no one can have contempt for that. I might sum up what I have said by saying that in his relations with both his culture and his client, the lawyer leads a life that at once requires and makes possible that he have an education of the fullest sort, and, if he takes his responsibilities seriously, he can offer such an education to others. Unlike the life of Callicles, Socrates, that is not a life "worthy of no one," but a life worthy of anyone.

$$
\text { ***** }
$$

This is one possible set of responses to the challenge that the Gorgias makes to the modern lawyer. For obvious reasons-an openness to refutation-I think it important to say that this is the best response that I can make. The reader may, of course, find it unsatisfactory, perhaps especially in its account of the relations between client and lawyer and its version of what it means to give oneself the mind of the brief-writer and case-maker. (And the image of the jars ceaselessly leaking, ceaselessly being filled, may be uncomfortably close to one's own office life.) But beyond the merits even of these important questions, I hope both that this paper has helped to make real to the reader a set of difficult questions first posed by others in ways not easily accessible to the reader only of English, and that it has suggested a way of involving oneself with a philosophical text, both on its terms and on one's own, that has some general value.

is somehow freer or better than the lawyer. The danger for the professor is that he will spend his life writing articles or books that are really little more than a series of briefs all on the side of his own unexamined biases and attitudes, something a lawyer can almost never do. 
What Plato teaches us in the end is that we cannot help speaking a language that is made by others, yet forms our mind; that we are responsible for how we speak and who we are; that self-conscious thought on these questions is among the most important tasks of a mature mind (or people); and that to establish a place of our own making from which cultural and ethical criticism can go on is essential to responsible life. We cannot escape the fact that whenever we speak we redefine for the moment the resources of our culture and in doing so establish a character for ourselves and a relation with another, the person to whom we speak. Who shall we be? What relation shall we have with our language? What kind of relations shall we have with others? These are the central questions of human life, and they are present with special force and clarity in the life of the lawyer. 